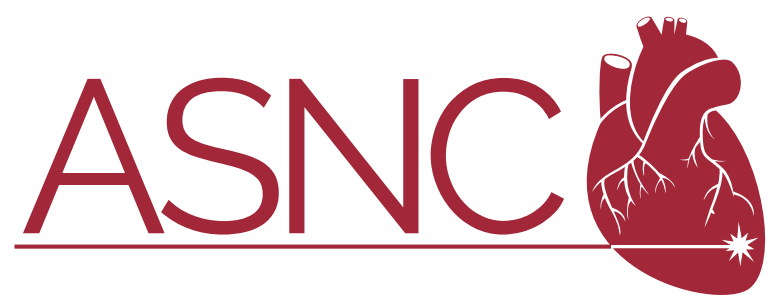

\title{
WHAT IS THIS IMAGE?
}

WHAT IS THIS IMAGE? 2021 : IMAGE 2
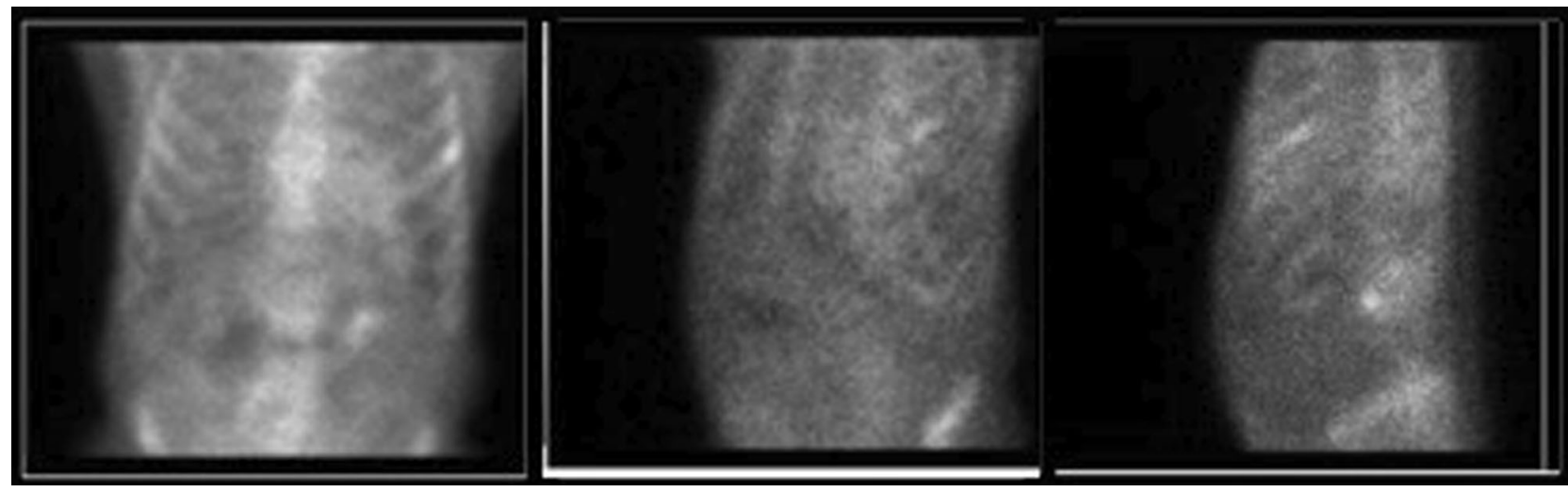

To submit your interpretation of this image, please visit www.asnc.org/WhatIsThisImage; here you will find further instructions, a link to the online survey, and details of the closing date. By a lottery, a winner will be selected among those with the correct or close to correct answers, and the winner will be announced-alongside the correct interpre tation-in the subsequent issue of JNC. Each bi-monthly winner will win an ASNC Gift Pack. At the end of the year,

and again by lottery, one winner among the year's winners will be selected; ASNC has graciously agreed to provide this person with free registration to the ASNC annual meeting.

Publisher's Note Springer Nature remains neutral with regard to jurisdictional claims in published maps and institutional affiliations. 